\title{
33
}

\section{Introduction of IT in School Management: Approaches, Preparation, Human and Political Aspects}

Discussion chaired by:

Ian Selwood ${ }^{a}$, Phil Wild ${ }^{b}$, Daniel Millin ${ }^{c}$

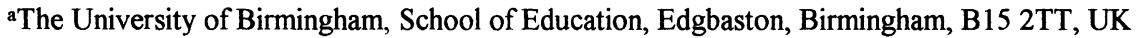

bEducation Department, Loughborough University, Loughborough, LE11 3TU, UK

'School of Education, Tel Aviv University, Tel Aviv, Israel

\section{INTRODUCTION}

The discussion group was asked to review the introduction of information technology into school management and administration from the viewpoint of approaches, preparation, human and political factors. The group met on two separate occasions. The first session was a general round table debate that centred on the distinction between the administrative and management functions of ITEM systems in use around the world, and also considered why management functions had not developed at the same rate as administrative functions. The second session was more directly focused on issues concerned with the assimilation of IT into school administration and management.

The report endeavours to summarise the wide ranging debate of the first session and details the points made in the more focused discussion of the second day.

\section{SESSION 1}

There was a general consensus that the political agenda can influence developments. IT implementation can become very intermingled with devolution of powers to schools, as in the UK and Australia. Accountability must be part of devolution and IT can help to provide the authorities with the information that they require but, systems developed in schools do not necessarily provide for this interchange of information. Systems must therefore be specified by the authorities and this can lead to 'big brother' anxieties. It was agreed that, whilst many schools throughout the world were using IT for administration, management uses were limited. Reasons suggested for this were:

- School managers might find computers threatening.

- Many systems concentrate on administration functions and do not provide for the necessary linkage into the management decision making of the institution.

- Administrative tasks were often separated on the IT based system even though in manual systems they overlap.

- Personal interests of staff might predominate over implementation of wider access to information.

- A lack of understanding of the management of change required to assimilate IT means that there is no overall strategy for IT utilisation. 
- School managers may not have been trained in using the information provided by ITEM systems to support their management decisions.

- It was suggested that research has shown that managers do not like making decisions on aggregated data but prefer to use intuition. They often feel that they have to react quickly without having the time needed to make use of the available information and fully consider the options.

- Accountability has lead to more 'management by committee' which might reduce the direct use of IT for decision making and planning.

- In many cases the introduction of ITEM is at the instigation of LEAs or Governments and change introduced by external agencies without adequate consultation does not work.

It was suggested that the use of IT for administration rather than management was a necessary first step to introducing the use of ITEM and that assimilation of any new system takes time. The benefits of using IT in Administration are more immediately tangible than those of management decisions based on the IT. This accounts for the more ready acceptance of administrative IT. However, this identified value of administrative IT needs to be extended into management functions. Other suggestions for overcoming resistance to change included:

- Assimilation needs to be carefully planned into the organisation

- New software should have functions more clearly identified as support for decision making

- Information provided by the software should link to identified management goals.

- An enlightened member of staff with vision can promote wider use.

- A realisation by managers that information systems might help to provide better quality time to use management data.

- A need for training to change the present mode of decision making.

- Technological training must go alongside management training.

- For successful assimilation of ITEM a positive attitude towards IT needs to be engendered in all staff through the use of IT as a personal productivity tool.

Reservations were expressed concerning the possible misuse of raw statistical data in educational decision making and IT based information could be used to compare pupils, teachers and schools in an inappropriate manner, further reinforcing 'big brother' fears. Information systems should be used to help inform, but educational decisions should be based on human judgement. 'Educational Atmosphere' cannot be computerised.

\section{SESSION 2}

Having considered the problems of the assimilation of ITEM the group felt that we should adopt a different approach in the second session and try to produce some guide-lines for its introduction, the preferred starting point being an examination of the goals of ITEM.

\section{GOALS}

The following goals for the introduction of IT into Educational Administration and Management were identified during the discussion:

- To increase the efficiency and effectiveness of the educational institution in order to provide a better service for all students. 
- To relieve teachers, management and support staff from mundane administrative tasks.

- To collect and provide accurate and up-to-date information in order to aid the planning and administration of the educational institution.

- To meet the increased requirements for reporting and accountability.

- To improve the manipulation and presentation of information for different audiences.

- To aid in the evaluation of students, teachers and schools within the limitations of the data and moderated by educational considerations.

- To automatically provide details of exceptional situations for management decisions.

\section{APPROACHES AND PREPARATION}

The following general headings were identified and are presented here as broad guide-lines. It was noted that this was not a linear and one off procedure but a continuous cyclical process, and the stages conceal very complex processes in which educational institutions could and possibly should use outside assistance.

1. Identify users.

2. Together with the users, review current and previous practice within the institution and the wider IT community.

3. Provide phased training relevant to the function of users.

4. Explain potential benefits to all staff.

5. Phase introduction (or extension of use) of ITEM application by application to ensure immediate rewards from use.

\section{CONCLUSION}

The above identifies many issues relating to the introduction of ITEM in schools. Factors that inhibit assimilation were discussed at length and are listed, as are many of the major suggestions made for overcoming resistance to change. It was also strongly felt, that in order to evaluate the effectiveness of ITEM there was a need for goals to be set prior to any change, and that adequate preparation for introducing or changing systems could not be over stressed. 